\title{
Time for something different: the Korean Journal of Anesthesiology commences EPUB ahead of print
}

\author{
Younsuk Lee $e^{1,2}$ \\ ${ }^{1}$ Department of Anesthesiology and Pain Medicine, Dongguk University Ilsan Hospital, ${ }^{2}$ D/M Statistics Institute, \\ Dongguk University, Goyang, Korea
}

The Korean Journal of Anesthesiology (KJA) is beginning EPUB ahead of print (EAOP). EPUB has become a lion in scientific journals. Since the KJA steering committee adopted online publication in 2010, we have published 11 volumes and 3 issues using the traditional "paper publication first, followed by online publication" approach. As an indicator of the low efficiency of that strategy, the publication lag of the KJA has become so long that we have been obliged to consider reform. While the rejection speed is adequate (Table 1), the publication speed has slowed to a crawl (Table 2). We believe that EAOP will increase the publication speed.

To explain the jargon of journals, journal publishers rate the efficiency of a journal based on both rejection speed and publication speed. There are three indicators of publication speed: ac-
Table 1. KJA Rejection Speed Indicators

\begin{tabular}{cccc}
\hline \multicolumn{4}{c}{ Rejection lag (days) } \\
\hline & $\begin{array}{c}\text { Total } \\
(\mathrm{n}=819)\end{array}$ & $\begin{array}{c}\text { In-house review* } \\
(\mathrm{n}=307)\end{array}$ & $\begin{array}{c}\text { Peer-review } \\
(\mathrm{n}=512)\end{array}$ \\
\hline 2011 & $38(26,73)$ & - & $38(26,73)$ \\
2012 & $50(22,53)$ & - & $35(22,53)$ \\
2013 & $16(5,30)$ & $5(3,10)$ & $29(22,65)$ \\
2014 & $10(6,26)$ & $6(4,7)$ & $29(19,50)$ \\
2015 & $10(7,31)$ & $7(6,10)$ & $43(27,70)$ \\
2016 & $8(5,15)$ & $6(4,9)$ & $32(23,41)$ \\
\hline
\end{tabular}

Values are the median (Q1, Q3). Rejection lag (days) = Received date to Rejected date. The dates are retrieved from the KJA online submission system. This began in 2012 after a 1-year test operation. KJA: Korean Journal of Anesthesiology. * Rejection by In-House Review was introduced in early 2013.

Table 2. KJA Publication Speed Indicators

\begin{tabular}{lcccc}
\hline & Acceptance lag (days) & Lead lag (days) & Publication lag (days) & PubMed lag (days) \\
\hline $2011(\mathrm{n}=73)$ & $62(45,91)$ & $178(165,196)$ & $241(212,273)$ & $31(22,33)$ \\
$2012(\mathrm{n}=139)$ & $76(54,108)$ & $213(155,308)$ & $314(231,383)$ & $16(15,22)$ \\
$2013(\mathrm{n}=142)$ & $75(52,106)$ & $212(183,298)$ & $319(257,385)$ & $15(14,19)$ \\
$2014(\mathrm{n}=154)$ & $70(47,104)$ & $213(173,393)$ & $325(241,462)$ & $15(9,21)$ \\
$2015(\mathrm{n}=79)$ & $67(53,95)$ & $173(127,298)$ & $266(193,368)$ & $9(9,14)$ \\
$2016(\mathrm{n}=31)$ & $66(47,102)$ & $205(131,270)$ & $273(219,370)$ & $21(13,21)$ \\
\hline
\end{tabular}

Values are the median (Q1, Q3). Acceptance lag (days) = Received date to Accepted date. Lead lag (days) = Accepted date to Publication date. Publication lag (days) = Acceptance lag + Lead lag. PubMed lag (days) = Publication date to PubMed data creation date. The analyses include 618 articles (original articles and case reports) published in the KJA for which the digital object identifiers were retrieved on the Scopus website on 11 June 2016. The "dates" information was batch queried from PubMed article pages using R ver. 3.3.0 (R Foundation for Statistical Computing. Austria) on 13 June 2016. KJA: Korean Journal of Anesthesiology.

Corresponding author: Younsuk Lee, M.D., Ph.D.

Department of Anesthesiology and Pain Medicine, Dongguk University Ilsan Hospital, D/M Statistics Institute, Dongguk University, 27, Donggukro, Ilsandong-gu, Goyang 10326, Korea

Tel: 82-31-961-7872, Fax: 82-31-961-7864, E-mail: ylee@dongguk.edu

ORCID: http://orcid.org/0000-0003-2488-5926

Korean J Anesthesiol 2016 August 69(4): 315-316

http://dx.doi.org/10.4097/kjae.2016.69.4.315

(c) This is an open-access article distributed under the terms of the Creative Commons Attribution Non-Commercial License (http://creativecommons.org/ licenses/by-nc/4.0/), which permits unrestricted non-commercial use, distribution, and reproduction in any medium, provided the original work is properly cited. 
ceptance lag (time between receiving and accepting an article), lead lag (time between acceptance and publication), and publication lag (time between receiving and publishing, equal to the acceptance lag plus the lead lag).

The most recent publication lag of the KJA exceeded 250 days, which is far greater than the instinctive threshold for timely publication. Although the acceptance lag depends on the reviewers, the lead lag depends on journal policy, which is where we have started our reforms. The KJA has maintained the old practice of saving accepted manuscripts to ensure that consistent numbers of articles are published in each volume. This practice requires an additional 45-60 days before publication and consists of several cycles of author proofreading, editor proofread- ing, author confirmation, and creation of the final PDF.

Tort et al. [1] showed that earlier online appearance of an article before publication increases the impact factor of a journal, while a long lead lag reduces both the efficiency and the impact factor under the old scenario of "publication-first, online-later." With our new practice of "online-first, publication-later," readers will be able to see our online manuscripts irrespective of the lead lag. Consequently, we will need to redefine the term 'lead lag' [2].

Every anesthesiology study and every manuscript conveys the authors' commitment to increasing medical knowledge and improving the practice of anesthesiology. Therefore, to ensure timely publication of their work, we are beginning EAOP in June 2016.

\section{References}

1. Tort AB, Targino ZH, Amaral OB. Rising publication delays inflate journal impact factors. PloS ONE 2012; 7: e53374.

2. Heneberg P. Effects of print publication lag in dual format journals on scientometric indicators. PloS ONE 2013; 8: e59877. 